\title{
Leaf gas exchange and grain yield of common bean exposed to spermidine under water stress
}

\author{
S. TORABIAN ${ }^{*},+$, M.R. SHAKIBA* ${ }^{*}$ A. DABBAGH MOHAMMADI NASAB ${ }^{*}$, and M. TOORCHI ${ }^{* *}$ \\ Department of Ecophysiology, Faculty of Agriculture, University of Tabriz, Tabriz 51666-16471, Iran* \\ Department of Plant Breeding and Biotechnology, Faculty of Agriculture, University of Tabriz, \\ Tabriz 51666-16471, Iran ${ }^{* *}$
}

\begin{abstract}
Three prevalent aliphatic polyamines (PAs) include putrescine, spermidine, and spermine; they are low-molecular-mass polycations involved in many physiological processes in plants, especially, under stressful conditions. In this experiment, three bean (Phaseolus vulgaris L.) genotypes were subjected to well-watered conditions and two moderate and severe water-stressed conditions with and without spermidine foliar application. Water stress reduced leaf relative water content (RWC), chlorophyll contents, stomatal conductance $\left(g_{\mathrm{s}}\right)$, intercellular $\mathrm{CO}_{2}$ concentration $\left(C_{\mathrm{i}}\right)$, transpiration rate, maximal quantum yield of PSII $\left(\mathrm{F}_{\mathrm{v}} / \mathrm{F}_{\mathrm{m}}\right)$, net photosynthetic rate $\left(P_{\mathrm{N}}\right)$, and finally grain yield of bean plants. However, spermidine application elevated RWC, $g_{\mathrm{s}}, C_{\mathrm{i}}, \mathrm{F}_{\mathrm{v}} / \mathrm{F}_{\mathrm{m}}$, and $P_{\mathrm{N}}$, which caused an increase in the grain yield and harvest index of bean plants under water stress. Overall, exogenous spermidine could be utilized to alleviate water stress through protection of photosynthetic pigments, increase of proline and carotenoid contents, and reduction of malondialdehyde content.
\end{abstract}

Additional key words: harvest index; number of pods; water deficit.

\section{Introduction}

Drought stress in plants is characterized by the continuous loss of water through transpiration and evaporation into the atmosphere, while the water uptake is decreased due to a reduced water content in soil (Abedi and Pakniyat 2010). The accessibility of sufficient amount of water is essential for plant growth and development. Consequently, water deficiency is a major factor limiting crop yield and biomass production. The first reaction of plants to a decline in soil moisture, before any detectable change in a leaf water potential, is stomatal closure (Chaves et al. 2003) as a response to drought that reduces leaf water loss. Moreover, photosynthesis is also known to be sensitive to drought stress. As water availability is reduced, many plants decline their leaf photosynthetic rate. Snider et al. (2014) reported that $P_{\mathrm{N}}$ was strongly influenced by $g_{\mathrm{s}}$, indicating that $g_{\mathrm{s}}$ is a major factor governing photosynthetic responses under drought stress. Negative effects of water limitation on stomatal closure and $P_{\mathrm{N}}$ result in a lower growth capacity and decrease in biomass accumulation (Benešová et al. 2012). The $\mathrm{F}_{\mathrm{v}} / \mathrm{F}_{\mathrm{m}}$ is taken as a parameter for the study of chloroplast development under normal and stress conditions (Misra et al. 2006). Centritto (2005) found that $\mathrm{F}_{\mathrm{v}} / \mathrm{F}_{\mathrm{m}}$ decreased under severe water deficit. Under severe water deficit, mostly correlated with increases of leaf temperature, light and excitation energy in PSII leading to photoinhibition, which ultimately leads to the lower quantum yield of PSII (Govindjee 1999). Reductions in leaf pigments induced by drought are considered to be an oxidative stress indicator, which might be attributed to pigment photo-oxidation, chlorophyll (Chl) degradation, and/or Chl synthesis deficiency (Sánchez-Rodríguez et al. 2012). During water deficit, excessive generation of reactive oxygen species (ROS), such as superoxide radical $\left(\mathrm{O}_{2}{ }^{--}\right)$, hydrogen peroxide $\left(\mathrm{H}_{2} \mathrm{O}_{2}\right)$, and hydroxyl radical $\left({ }^{\circ} \mathrm{OH}\right)$ occurs, which causes membrane lipid peroxidation leading to irreparable metabolic and structural dysfunctions and cell death (Miller et al. 2010). Furthermore, the increase in the concentration of organic solutes, such as proline, sucrose, and other soluble sugars may stabilize the cellular osmotic pressure under drought stress (Sucre and Suárez 2011).

Received 21 July, accepted 7 February 2018, published as online-first 21 June 2018.

${ }^{+}$Corresponding author; e-mail: s.torabian@ag.iut.ac.ir

Abbreviations: Car - carotenoid; $\mathrm{Chl}-$ chlorophyll; $C_{\mathrm{i}}-$ intercellular $\mathrm{CO}_{2}$ concentration; $E$ - transpiration rate; $\mathrm{F}_{\mathrm{v}} / \mathrm{F}_{\mathrm{m}}-$ maximum photochemical efficiency of PSII; $g_{\mathrm{s}}$ - stomatal conductance; HI - harvest index; MDA - malondialdehyde; MWD - moderate water deficit; NC - normal conditions, PAs - polyamines; $P_{\mathrm{N}}-$ net photosynthetic rate; ROS - reactive oxygen species; RWC - relative water content; SWD - severe water deficit; WUE - water-use efficiency; WUEi - intrinsic water-use efficiency.

Acknowledgements: This research was supported by the Faculty of Agriculture, University of Tabriz, Tabriz, Iran. The authors appreciate Shiva Torabian to help in fieldwork and collecting data. 
PAs, a group of low-molecular-mass polycations, are found in living cells. The common PAs in plants are spermidine, spermine, and their precursor, putrescine (Groppa and Benavides 2008). They are involved in many physiological processes, such as growth, morphogenesis, secondary metabolism, senescence, and apoptosis (Kusano et al. 2008). In recent years, attention has been focused on the role of polyamines in plants defense against abiotic stress (Alcázar et al. 2011, Kusano et al. 2008). Droughttolerant plants generally increase endogenous PAs content or metabolism more than sensitive plants do in response to drought stress (Alcázar et al. 2011). PAs may stabilize membranes, scavenge free radicals, modulate the activities of certain ion channels, and control many aspects of DNA, RNA, and protein turnover under water stress (Groppa and Benavides 2008, Alcázar et al. 2011). In addition, exogenous application of PAs enhanced drought tolerance of rice (Yin et al. 2014), and creeping bentgrass (Shukla et al. 2015). Farooq et al. (2009) found that exogenously applied PA improves leaf water status, photosynthesis, and membrane properties, thereby enhancing the drought tolerance of rice. There are several lines of evidence supporting the relationship between PAs and photosynthesis. The conjugation of PAs to photosynthetic complexes and

\section{Materials and methods}

Plants, growth conditions and treatments: The experiment was conducted on a farm in Research Center of Agricultural Science and Natural Resources, Isfahan, Iran $\left(32^{\circ} 40^{\prime} \mathrm{N}, 51^{\circ} 48^{\prime} \mathrm{E}\right.$, and $1,590 \mathrm{~m}$ a. s. 1.) during the beangrowing season (May-August) in 2014 and 2015. Some local climate data during the growing season are presented in the text table below. The soil type of this area is silt loam with a bulk density of $1.4 \mathrm{~g} \mathrm{~cm}^{-3}$ and $\mathrm{pH}$ 7.9. The experimental design was a randomized complete block with a split-plot arrangement of treatments with three replications. Main plot corresponded to water stress levels and subplots to three genotypes and spermidine. Fertilizer (compound fertilizer, $\mathrm{KNO}_{3}$ and $\mathrm{P}_{2} \mathrm{O}_{5}$ ) was applied prior to planting to reach a local favorable nutrition. Then, field of study was ploughed three times using disc before planting. Plot dimension was $4 \times 2.5 \mathrm{~m}$ and consisted of seven rows with $10 \mathrm{~cm}$ row spacing, and $25 \mathrm{~cm}$ distance between plants in a row. Three common bean genotypes, Akhtar (red), Pak (white), and COS12 (kidney) were proteins is catalyzed by trans-glutaminase and leads to enhanced photosynthetic activity under stress conditions (Ioannidis et al. 2012). It is well established that exogenous PAs can improve the photosynthetic capacity by increasing the photochemical efficiency of PSII under salinity (Zhang et al. 2009). Duan et al. (2006) reported that PSII activity of wheat was preserved by spermidine during water stress. Moreover, spermidine induced an increase in both total $\mathrm{Chl}$ and $\mathrm{Chl} a / b$ ratios as compared to spermidine untreated, salt-stressed plants (Chattopadhayay et al. 2002). They demonstrated that at physiological concentrations, spermidine and spermine considerably prevented Chl loss and downregulated chloroplastencoded genes. Similarly, it was reported that spermidine mitigated the degradation of $\mathrm{Chl}$ in salt-stressed rice (Roychoudhury et al. 2011). Gupta and Gupta (2011) indicated that exogenously applied putrescine enhanced a plant height, leaf area, grain number, grain mass, grain yield, and biological yield of wheat under normal as well as under water-stress conditions. Accordingly, the present study was aimed to determine the role of spermidine as a PA in drought tolerance in three common bean genotypes with reference to pigment contents, photosynthetic characteristics, and yield as well as yield components.

obtained from the National Bean Research Station of Khomain, Iran. These are the most important genotypes in Iran, which are cultivated widely by farmers. Surface was sterilized with $2 \mathrm{~g}$ (Benomyl) $\mathrm{kg}^{-1}$ for $10 \mathrm{~min}$, then rinsed with distilled water. Three water stress levels were set up based on evaporation from class A pan: irrigation after 60 $\mathrm{mm}$ evaporation (normal conditions, $\mathrm{NC}$ ), and irrigation after $90 \mathrm{~mm}$ and $120 \mathrm{~mm}$ evaporation [moderate (MWD) and severe water deficit (SWD)] after emergence of the third trifoliate leaf. Two spermidine treatments [control and $1 \mathrm{mM}$ spermidine (St Louis, MO, USA)] were sprayed after the emergence of the seventh trifoliate by backpack sprayer. As an average, each plant received $100 \mathrm{ml}$ solutions each time. Weeding and routine crop management were performed manually. Thirty days after the foliar spray by spermidine (at the flowering stage), samplings for bio-molecule and pigment estimations were carried out.

Mean temperature, relative humidity and rainfall for the 2014 and 2015 growing seasons.

\begin{tabular}{|c|c|c|c|c|c|c|}
\hline Month & $\begin{array}{l}\text { Mean temperature } \\
{\left[{ }^{\circ} \mathrm{C}\right]} \\
\text { First season }\end{array}$ & $\begin{array}{l}\text { Relative humidity } \\
{[\%]}\end{array}$ & $\begin{array}{l}\text { Rainfall } \\
{[\mathrm{mm}]}\end{array}$ & $\begin{array}{l}\text { Mean temperature } \\
{\left[{ }^{\circ} \mathrm{C}\right]} \\
\text { Second season }\end{array}$ & $\begin{array}{l}\text { Relative humidity } \\
{[\%]}\end{array}$ & $\begin{array}{l}\text { Rainfall } \\
{[\mathrm{mm}]}\end{array}$ \\
\hline May & 20.2 & 46 & 21.9 & 18.4 & 47.5 & 24.4 \\
\hline June & 28.9 & 21.5 & 0 & 26.3 & 24 & 10.4 \\
\hline July & 28.2 & 47 & 12.5 & 29.6 & 20.5 & 0 \\
\hline August & 27.8 & 14.5 & 0 & 28.6 & 24 & 0 \\
\hline September & 28.9 & 14.5 & 0 & 25 & 22.5 & 0 \\
\hline
\end{tabular}


Leaf RWC, contents of $\mathrm{Chl}$ and Car: Representative samples were collected from top-most fully expanded leaves and quickly weighed (leaf FM). Then the samples were immediately hydrated to full turgidity for $3-4 \mathrm{~h}$ by floating on deionized water in a closed Petri dish under normal room light and temperature. Afterwards, hydrated samples were well dried with filter tissue paper and weighed to obtain fully turgid mass (leaf TM). Samples were oven-dried for a minimum of $24 \mathrm{~h} \mathrm{at} 70^{\circ} \mathrm{C}$ to determine dry mass (leaf DM). Relative water content was calculated as RWC $=[($ leaf FM - leaf DM $) /($ leaf TM leaf DM) $\times 100$. Chl and Car contents were determined according to the method described by Lichtenthaler and Wellburn (1983). Leaf discs were placed in $15-\mathrm{mL}$ tubes containing $80 \%$ acetone. The tubes were kept in darkness for about $48 \mathrm{~h}$ until the discs were completely whitened. Absorption of the extracts at 470,663, and $646 \mathrm{~nm}$ were determined using a $U V-2450$ spectrophotometer (Hitachi, Tokyo, Japan).

Proline and malondialdehyde (MDA) contents: Proline was determined following the method of Bates et al. (1973). Fresh leaves were extracted in sulphosalicylic acid, an equal volume of glacial acetic acid and ninhydrin solutions were added to the extract. The sample was heated at $100^{\circ} \mathrm{C}$, and then $5 \mathrm{ml}$ of toluene was added. The absorbance of the toluene layer was read at $528 \mathrm{~nm}$, on a spectrophotometer (Hitachi, Tokyo, Japan). For the MDA assay, fresh leaves were homogenized in $5 \mathrm{~mL}$ of 100 $\mathrm{g}$ (trichloroacetic acid) $\mathrm{L}^{-1}$ containing $250 \mathrm{~g}$ (thiobarbituric acid) $\mathrm{L}^{-1}$, and centrifuged at $20,000 \times g$ for $25 \min \left(4^{\circ} \mathrm{C}\right)$. The mixture was heated to $95^{\circ} \mathrm{C}$ for $30 \mathrm{~min}$, and then cooled quickly in an ice-bath. Subsequently, samples were centrifuged at $10,000 \times g$ for $10 \min \left(4^{\circ} \mathrm{C}\right)$ and the supernatant absorbance was read at $532 \mathrm{~nm}$. The value for the nonspecific absorption at $600 \mathrm{~nm}$ was subtracted from the $532 \mathrm{~nm}$ reading. The concentration of MDA was

\section{Results}

Leaf RWC, contents of Chl and Car: The statistical analysis of the data revealed that RWC affected by water deficit and spermidine treatments. Foliar application of spermidine increased leaf RWC under both MWD and SWD significantly, but the extent of the enhancement was greater under SWD than that of MWD. Contrary, leaf RWC of unstressed plants was not affected by spermidine spray (Fig. 1A).

In order to better understand the roles of water stress and spermidine for pigment contents in bean, the contents of Chl $a, b$, and Car were determined. Water deficit and spermidine strongly affected leaf $\mathrm{Chl}$ and Car contents. There are no 2- or 3-way interactive effects of year, water deficit, genotype, and spermidine on $\mathrm{Chl}$ and Car contents (Table 1). Under MWD and SWD, leaf Chl was reduced on average by 14 and $34 \%$, respectively, compared to well- calculated using an extinction coefficient of $155 \mathrm{mM}^{-1} \mathrm{~cm}^{-1}$ (Rosales et al. 2009).

$\mathbf{F}_{\mathrm{v}} / \mathbf{F}_{\mathrm{m}}$ and gas-exchange parameters: At the flowering stage, Chl fluorescence parameters, including maximum $\left(\mathrm{F}_{\mathrm{m}}\right)$ and minimum $\left(\mathrm{F}_{0}\right)$ fluorescence along with the maximum efficiency of PSII $\left[\left(\mathrm{F}_{\mathrm{m}}-\mathrm{F}_{0}\right) / \mathrm{F}_{\mathrm{m}}\right]$, were measured on fully expanded, attached leaves after darkadaptation for 20 min using a portable Chl fluorometer (Opti-Sciences, Inc., Hudson, NH, USA). Photosynthetic gas-exchange rates were measured with a $L i-6400$ portable photosynthesis system (LICOR Inc., Lincoln, NE, USA) at the flowering stage between 10:00 and 13:00 h. The $P_{\mathrm{N}}, g_{\mathrm{s}}$, $C_{\mathrm{i}}$, and transpiration rate $(E)$ were measured by maintaining air temperature at $25^{\circ} \mathrm{C}$, the relative humidity at $50-60 \%$, and at light intensity of $1,200 \mu \mathrm{mol}$ (photon) $\mathrm{m}^{-2} \mathrm{~s}^{-1}$. These measurements were made on four fully expanded leaves per plants and were taken, when a steady state was obtained.

WUE and WUE $E_{\mathrm{i}}$ : WUE was calculated as a ratio of $P_{\mathrm{N}}$ to $E$ (Bertolde et al. 2012) and as an estimate of $\mathrm{WUE}_{\mathrm{i}}$ the ratio of $P_{\mathrm{N}}$ to $g_{\mathrm{s}}$ was taken (Rouhi et al. 2007).

Yield and yield components: At harvest, the number of pods per plant, number of grains per pod, 100-grain mass, grain yield, and harvest index of bean genotypes were determined. Harvest index (HI) was calculated as: (grain yield/biological yield) $\times 100$.

Statistical analysis: All measurements were done in triplicate, and the results were averaged and processed by one-way variance analysis test (ANOVA) using a Statistical Analysis Software Version 9.1 (SAS Institute Inc., Cary, North Carolina, USA). For the comparison of data means, least significant difference (LSD) test was used at the $P \leq 0.05$ level of significance.

watered plants. However, the leaf Car content increased under MWD and SWD by 1.3 and 2.6 folds, respectively (Table 1). In this study, exposure of bean plants to spermidine considerably elevated $\mathrm{Chl}$ and Car contents. According to our results presented in Table 1, Chl $a, b$, total and Car contents were improved by 15, 10, 14, and $18 \%$ by spermidine relative to control plants. Meanwhile, year, water stress, genotype, and spermidine had no effects on $\mathrm{Chl} a / b$ ratio.

Proline and MDA contents: Consistent with the results, year, water stress levels, genotypes, spermidine, and interaction of water deficit $\times$ genotype had a significant influence on the content of proline in leaves. As shown in Fig. $1 B$, the proline content was positively correlated with water scarcity. With increasing water deficit intensity, 


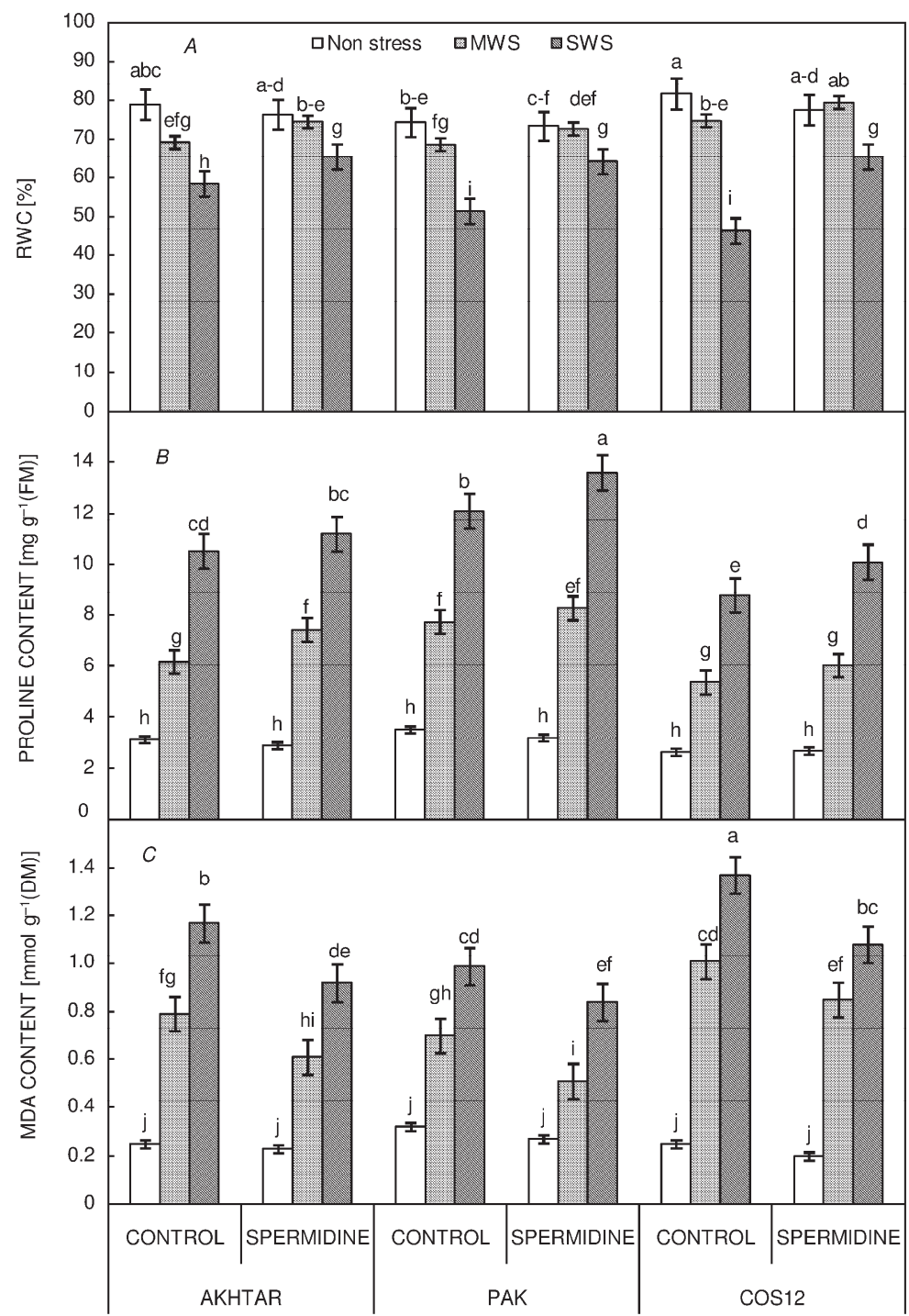

Fig. 1. Effect of spermidine application on relative water content (RWC) $(A)$, proline $(B)$ and malondialdehyde (MDA) $(C)$ contents of common bean genotypes under water stress levels. Columns with the same letter(s) are not significantly different at $P \leq 0.05$ probability. Bars on the columns are means \pm standard error. MWS - moderate water stress, SWS - severe water stress. the proline content increased; whereas, the value of increment varied among genotypes. Under SWD, the highest proline content belonged to Pak. Additionally, no conspicuous difference in the proline contents was observed under non-stressed condition. Compared with control, the spermidine-sprayed plants showed slightly higher proline contents.

Variations in the MDA content, which indicated lipid peroxidation, are presented in Fig. 1C. Substantial effects of water stress levels, genotypes, spermidine, and water stress $\times$ genotypes on leaf MDA content were found. The MDA content under MWD and SWD strongly increased. Nonetheless, the extent of MDA increment was different between bean genotypes under water deficit. The maximum amount of MDA was recorded in COS12 under SWD. Exogenous application of spermidine appreciably diminished the leaf MDA content by $19 \%$ compared with control, irrespective of water stress level and genotype.
$\mathbf{F}_{\mathbf{v}} / \mathbf{F}_{\mathbf{m}}$ and gas-exchange parameters: Results of $A N O V A$ for quantum yield showed that $\mathrm{F}_{\mathrm{v}} / \mathrm{F}_{\mathrm{m}}$ was notably affected by water stress and spermidine. There was no significant difference in $F_{v} / F_{m}$ between genotypes as indicated in Table 1. Water stress treatments caused a remarkable decrease of $\mathrm{F}_{\mathrm{v}} / \mathrm{F}_{\mathrm{m}}$, which was $9 \%$ under MWD and was $22 \%$ under SWD compared with no stress treatment. Averaged across water stress and genotypes, $\mathrm{F}_{\mathrm{v}} / \mathrm{F}_{\mathrm{m}}$ was improved by spermidine application by $6 \%$ compared with control. There were no 2- or 3-way interactive effects of year, water deficit, genotype, and spermidine on $\mathrm{F}_{\mathrm{v}} / \mathrm{F}_{\mathrm{m}}$ (Table 1).

In order to determine the water stress and spermidine effects over the gas-exchange parameters of three common bean genotypes, $P_{\mathrm{N}}, g_{\mathrm{s}}, C_{\mathrm{i}}$, and $E$ were measured. Water deficit, genotype, and spermidine considerably affected $P_{\mathrm{N}}, g_{\mathrm{s}}, C_{\mathrm{i}}$, and $E$. The interactive effects of water deficit $\times$ genotype on $P_{\mathrm{N}}, g_{\mathrm{s}}$, and $E$, and water deficit $\times$ spermidine 
Table 1. Effects of spermidine on chlorophyll (Chl) $a, b$ and total contents, $\mathrm{Chl} a / b$ ratio, carotenoid (Car) content, and maximal quantum yield of PSII $\left(\mathrm{F}_{\mathrm{v}} / \mathrm{F}_{\mathrm{m}}\right)$ of common bean genotypes under water deficit. Values are means \pm standard errors. Means followed by the same letter in the same column are not significantly different at the $5 \%$ probability level by LSD test. Analysis of variance $(A N O V A) P$ values were shown $(P<0.05$ - significant; $P<0.01$ - markedly significant; $P>0.05$ - not significant). MWS - moderate water stress, SWS severe water stress; FM - fresh mass.

\begin{tabular}{|c|c|c|c|c|c|c|c|}
\hline Treatment & df & $\begin{array}{l}\text { Chl } a \\
{\left[\mathrm{mg} \mathrm{g}^{-1}(\mathrm{FM})\right]}\end{array}$ & $\begin{array}{l}\text { Chl } b \\
{\left[\mathrm{mg} \mathrm{g}^{-1}(\mathrm{FM})\right]}\end{array}$ & $\begin{array}{l}\text { Total Chl } \\
{\left[\mathrm{mg} \mathrm{g}^{-1}(\mathrm{FM})\right]}\end{array}$ & Chl $a / b$ & $\begin{array}{l}\text { Car } \\
{\left[\mathrm{mg} \mathrm{g}^{-1}(\mathrm{FM})\right]}\end{array}$ & $\mathrm{F}_{\mathrm{v}} / \mathrm{F}_{\mathrm{m}}$ \\
\hline \multicolumn{8}{|l|}{ Water deficit } \\
\hline No stress & & $4.76 \pm 0.14^{\mathrm{a}}$ & $2.29 \pm 0.06^{\mathrm{a}}$ & $7.05 \pm 0.06^{\mathrm{a}}$ & $2.09 \pm 0.08^{\mathrm{a}}$ & $0.23 \pm 0.03^{\mathrm{c}}$ & $0.77 \pm 0.01^{\mathrm{a}}$ \\
\hline MWS & & $4.05 \pm 0.15^{b}$ & $1.96 \pm 0.05^{\mathrm{b}}$ & $6.01 \pm 0.05^{\mathrm{b}}$ & $2.03 \pm 0.08^{\mathrm{a}}$ & $0.55 \pm 0.03^{b}$ & $0.70 \pm 0.02^{b}$ \\
\hline SWS & & $3.07 \pm 0.14^{\mathrm{c}}$ & $1.35 \pm 0.05^{\mathrm{c}}$ & $4.42 \pm 0.05^{\mathrm{c}}$ & $2.36 \pm 0.07^{\mathrm{a}}$ & $0.83 \pm 0.03^{\mathrm{a}}$ & $0.60 \pm 0.01^{\mathrm{c}}$ \\
\hline \multicolumn{8}{|l|}{ Spermidine } \\
\hline No spray & & $3.68 \pm 0.10^{\mathrm{b}}$ & $1.77 \pm 0.07^{\mathrm{b}}$ & $5.45 \pm 0.04^{b}$ & $2.14 \pm 0.06^{\mathrm{a}}$ & $0.49 \pm 0.04^{b}$ & $0.67 \pm 0.01^{b}$ \\
\hline $1 \mathrm{mM}$ & & $4.24 \pm 0.11^{\mathrm{a}}$ & $1.96 \pm 0.04^{\mathrm{a}}$ & $6.21 \pm 0.05^{\mathrm{a}}$ & $2.23 \pm 0.08^{\mathrm{a}}$ & $0.58 \pm 0.03^{\mathrm{a}}$ & $0.71 \pm 0.01^{\mathrm{a}}$ \\
\hline \multicolumn{8}{|l|}{ Genotype } \\
\hline Akhtar & & $3.98 \pm 0.11 \mathrm{a}$ & $1.91 \pm 0.04^{\mathrm{a}}$ & $5.59 \pm 0.06^{\mathrm{a}}$ & $2.13 \pm 0.07^{\mathrm{a}}$ & $0.51 \pm 0.04^{b}$ & $0.69 \pm 0.02^{\mathrm{a}}$ \\
\hline Pak & & $4.06 \pm 0.12^{\mathrm{a}}$ & $1.9 \pm 0.05^{\mathrm{a}}$ & $5.97 \pm 0.05^{\mathrm{a}}$ & $2.2 \pm 0.06^{\mathrm{a}}$ & $0.59 \pm 0.03^{\mathrm{a}}$ & $0.70 \pm 0.01^{\mathrm{a}}$ \\
\hline $\operatorname{Cos} 12$ & & $3.83 \pm 0.15^{\mathrm{a}}$ & $1.79 \pm 0.06^{\mathrm{a}}$ & $5.62 \pm 0.06^{\mathrm{a}}$ & $2.23 \pm 0.07^{\mathrm{a}}$ & $0.53 \pm 0.04^{\mathrm{ab}}$ & $0.68 \pm 0.01^{\mathrm{a}}$ \\
\hline \multicolumn{8}{|c|}{ Significance test of variations source ( $P$ values) } \\
\hline Year $(Y)$ & 1 & 0.42 & 0.35 & 0.28 & 0.32 & 0.59 & 0.44 \\
\hline Water deficit (W) & 2 & $<0.01$ & $<0.01$ & $<0.01$ & 0.15 & $<0.01$ & $<0.01$ \\
\hline Genotype $(\mathrm{G})$ & 2 & 0.49 & 0.08 & 0.19 & 0.84 & 0.08 & 0.54 \\
\hline Spernidine $(\mathrm{S})$ & 1 & $<0.01$ & $<0.01$ & $<0.01$ & 0.47 & $<0.01$ & $<0.01$ \\
\hline $\mathrm{Y} \times \mathrm{W}$ & 2 & 0.36 & 0.17 & 0.26 & 0.25 & 0.21 & 0.48 \\
\hline $\mathrm{Y} \times \mathrm{G}$ & 2 & 0.49 & 0.49 & 0.58 & 0.45 & 0.03 & 0.42 \\
\hline $\mathrm{Y} \times \mathrm{S}$ & 1 & 0.03 & 0.95 & 0.06 & 0.07 & 0.34 & 0.34 \\
\hline $\mathrm{W} \times \mathrm{G}$ & 4 & 0.72 & 0.38 & 0.41 & 0.98 & 0.77 & 0.86 \\
\hline $\mathrm{W} \times \mathrm{S}$ & 2 & 0.88 & 0.38 & 0.97 & 0.84 & 0.51 & 0.60 \\
\hline $\mathrm{G} \times \mathrm{S}$ & 2 & 0.97 & 0.71 & 0.97 & 0.74 & 0.62 & 0.93 \\
\hline $\mathrm{Y} \times \mathrm{W} \times \mathrm{S}$ & 2 & 0.96 & 0.57 & 0.90 & 0.98 & 0.33 & 0.71 \\
\hline $\mathrm{Y} \times \mathrm{S} \times \mathrm{G}$ & 2 & 0.73 & 0.79 & 0.64 & 0.87 & 0.99 & 0.88 \\
\hline $\mathrm{Y} \times \mathrm{W} \times \mathrm{G}$ & 4 & 0.96 & 0.77 & 0.97 & 0.59 & 0.57 & 0.95 \\
\hline $\mathrm{W} \times \mathrm{G} \times \mathrm{S}$ & 4 & 0.99 & 0.73 & 0.99 & 0.78 & 0.53 & 0.92 \\
\hline $\mathrm{Y} \times \mathrm{W} \times \mathrm{S} \times \mathrm{G}$ & 4 & 0.97 & 0.78 & 0.99 & 0.92 & 0.87 & 0.91 \\
\hline
\end{tabular}

on $E$ were also detected (Table 2). Regardless of genotype and spermidine, $P_{\mathrm{N}}, g_{\mathrm{s}}, C_{\mathrm{i}}$, and $E$ noticeably declined in the plants exposed to water stress conditions. Averaged across water deficit and genotype, gas-exchange parameters were elevated when plants were exposed to spermidine. According to Table 2, the highest value of photosynthetic parameters was observed in Pak with spermidine under well-watered plants, while the lowest value belonged to COS12 without spermidine under SWD. Averaged over the genotypes, usage of spermidine increased $E$ differently, when plants were subjected to water deficit. Application of spermidine enhanced $E$ by 8,22 , and $32 \%$ under no stress, MWD, and SWD, respectively (Table 2).

WUE and WUE $E_{\mathrm{i}}$ : Water deficit and genotype significantly affected WUE; however, spermidine and interactive effects of water deficit $\times$ genotype also influenced $W_{U E}$. As an average, severe water deficit increased WUE by $13 \%$ in comparison with well-watered beans, while there was no considerable difference between well-watered and MWD treatments. The maximum WUE was recorded in COS12 under SWD (Table 2). Irrespective of spermidine,
$\mathrm{WUE}_{\mathrm{i}}$ varied markedly among the bean genotypes when exposed to three water stress treatments. Under MWD, WUE $_{i}$ of all genotypes was reduced; however, under SWD, WUE $\mathrm{i}_{\mathrm{i}}$ of Akhtar and Pak genotypes increased compared with non-stressed plants (Table 2). Averaged across water stress and genotypes, foliar application of spermidine increased the $\mathrm{WUE}_{\mathrm{i}}$ by 7\%; however, spermidine usage had no significant effects on the WUE of bean genotypes.

Yield and yield components: Fig. 2 illustrates the changes in the yield and yield components of bean genotypes at the harvest stage. Water deficit, genotype, spermidine, and interactive effects of water deficit $x$ genotype were noticeable on the number of pods per plant, number of grains per pod, 100-grain mass, and grain yield. The interactive effect of water deficit $\times$ spermidine on 100 -grain mass was also detected. Water deficit conditions disrupted yield-related traits in terms of the number of pods and grains per plant, 100-grain mass, and grain yield in comparison to well-watered treatment. The extents of reductions under MWD in Akhtar, Pak, and COS12 were 


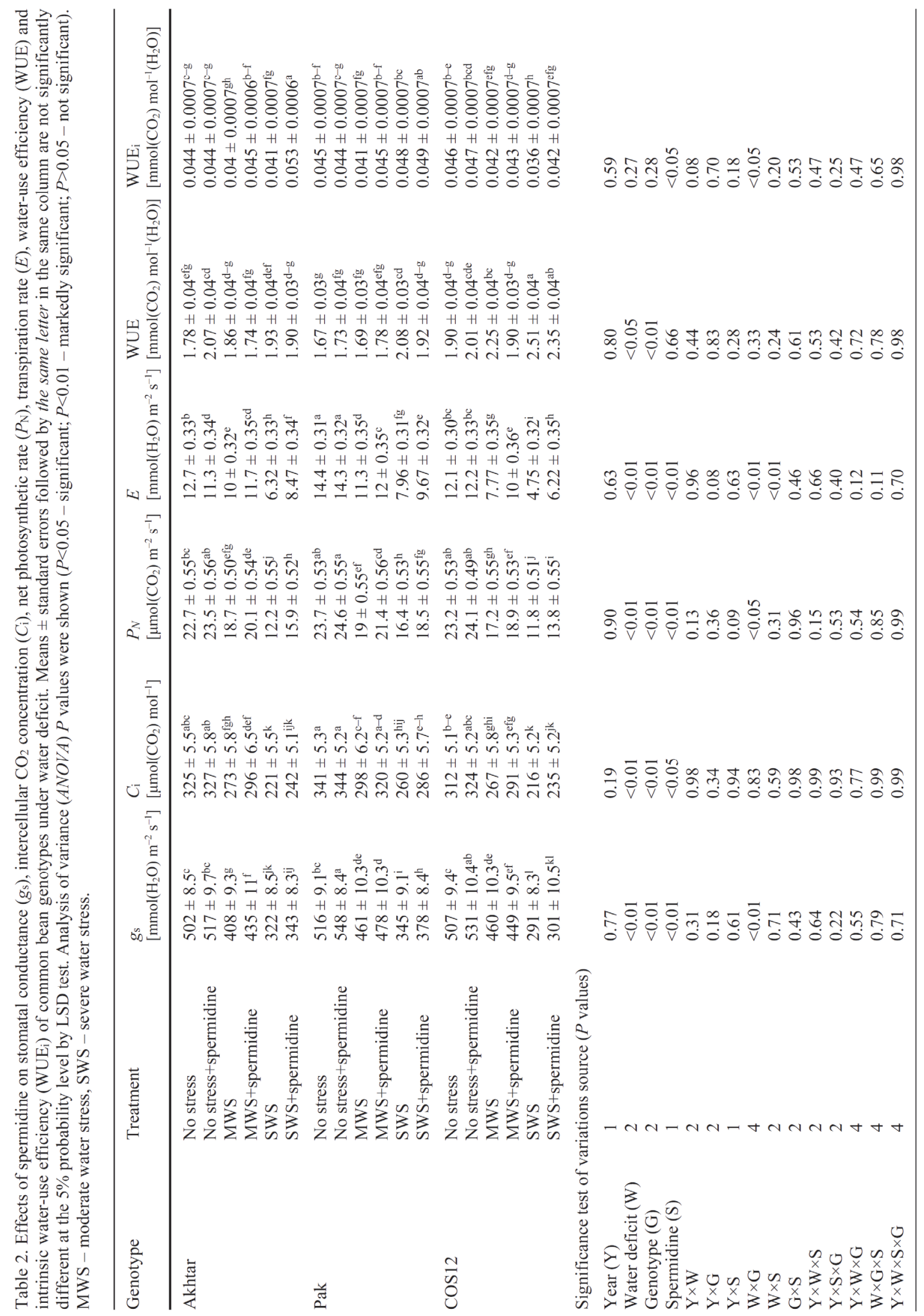




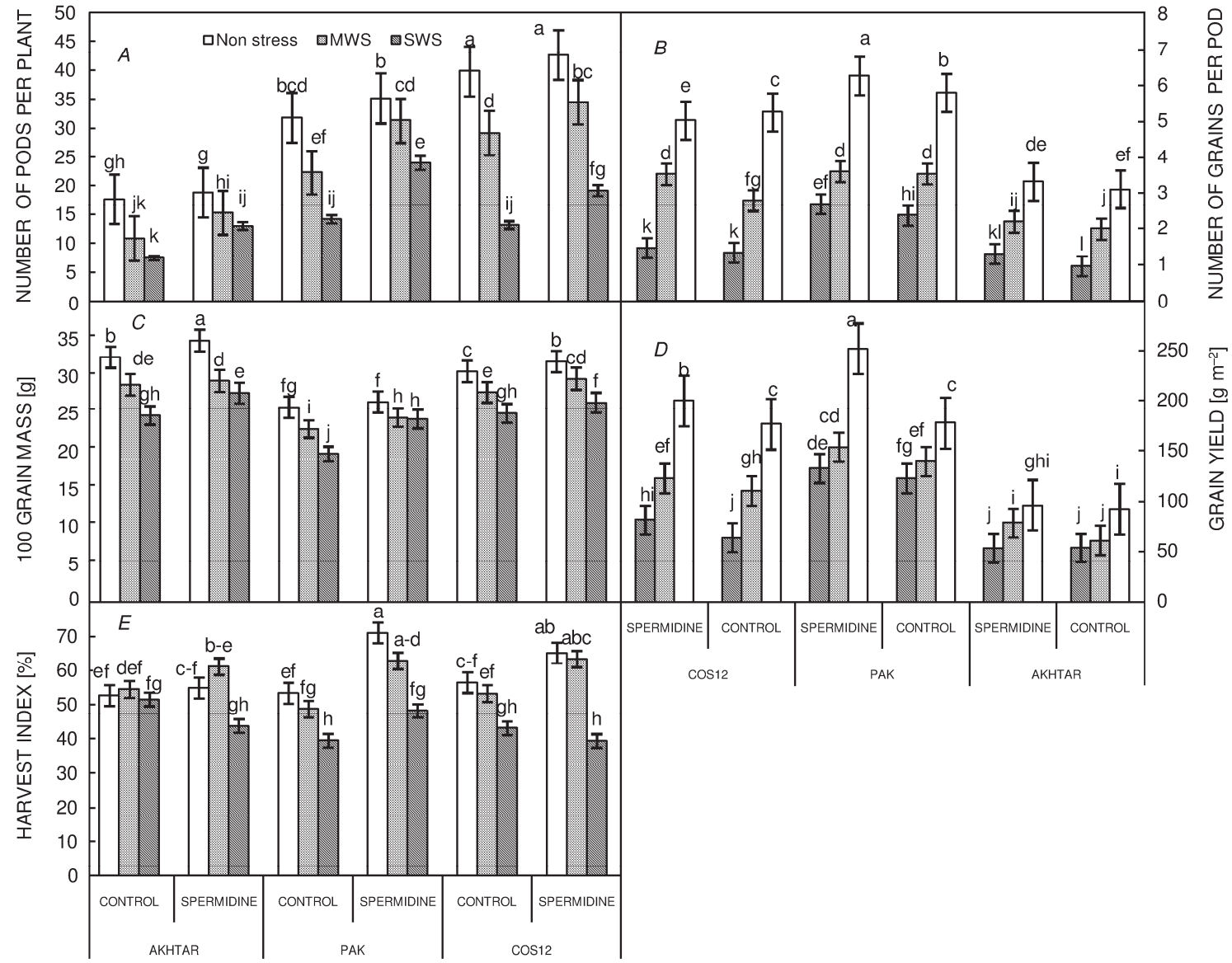

Fig. 2. Effect of spermidine application on number of pod per plant $(A)$, number of grain per pod $(B), 100$-grain mass $(C)$, grain yield $(D)$, and harvest index $(\mathrm{HI})(E)$ of common bean genotypes under water stress levels. Columns with the same letter $(S)$ are not significantly different at $P \leq 0.05$ probability. Bars on the columns are means \pm standard error. MWS - moderate water stress, SWS severe water stress

28,20 , and $24 \%$ and 43,43 , and $69 \%$, respectively, under SWD for the number of pods per plant (Fig. $2 A$ ). For number of grains per pod, the values declined in Akhtar, Pak and COS12 by 35, 41, and 38\% under MWD; while they were 64,58 , and $72 \%$, respectively, under SWD (Fig. $2 B$ ). The reductions in the extent of the 100-grain mass in Akhtar, Pak, and COS12 under MWD were 13, 9, and $8 \%$, and under SWD, the reductions were 22,17 , and $18 \%$, respectively, compared with non-stressed plants (Fig. 2C). Finally, the reductions in grain yield in Akhtar, Pak, and COS12 were 24, 31, and 36\% under MWD, and 42 , 41, and 60\%, respectively, under SWD (Fig. 2D).

Averaged over water stress and genotypes, when bean plants were sprayed with spermidine, the number of pods per plant, number of grains per pod, 100-grain mass, and grain yield improved by $25,8,7$, and $31 \%$, respectively,

\section{Discussion}

Water deficit is a well-known environmental stress factor that restricts the growth and yield of crop plants worldwide and can trigger a series of physiological and biochemical compared with control. Although exogenous application of spermidine increased 100-grain mass in plants under well-watered and water-deficit conditions, the extents of increment varied. A higher (14\%) 100-grain mass was observed in spermidine-treated plants compared with control in response to SWD; this was the greatest enhancement (Fig. 2C).

Water deficit and spermidine considerably affected HI of bean plants. There were no 2- or 3-way interactive effects of year, water deficit, genotype, and spermidine on HI. Averaged across genotype and spermidine, HI noticeably declined in the plants subjected to water stress conditions, especially under SWD. Moreover, HI was enhanced approximately by $12 \%$ when plants were exposed to spermidine, irrespective of water stress and genotype (Fig. 2E).

responses in plants (Yue et al. 2012). The main physiological and biochemical characteristics are not limited to stomatal closure, decrease in tha $\mathrm{Chl}$ content, 
reduction in transpiration, and inhibition of photosynthesis (Nezhadahmadi et al. 2013). Under water deficit, decreases in leaf RWC and water potential induce stomatal closure, leading to a reduction in $\mathrm{CO}_{2}$ availability and consequently to a decline in $P_{\mathrm{N}}$ and WUE (Bota et al. 2004). The first response of plants to soil moisture reduction is stomatal closure (Chaves et al. 2003). Stomatal closure and down-regulation of photosynthesis are both common responses of plants to drought (Dietz and Pfannschmidt 2011). For common bean, the values of RWC, $g_{\mathrm{s}}, C_{\mathrm{i}}, E$, and $P_{\mathrm{N}}$ were significantly diminished by water-stress treatments in the present study. These results suggest that the diminution of RWC in concert with the decline of $g_{\mathrm{s}} E$, and $C_{\mathrm{i}}$ contributed to the significant decrease in $P_{\mathrm{N}}$ under water scarcity. Chl fluorescence reflects the maximal efficiency of excitation energy captured by open PSII reaction center. Fluorescence determination has become a widely used method to study the functioning of the photosynthetic apparatus and is a powerful tool to study the responses of plants to environmental stress (Massacci et al. 2008). Decrease in PSII quantum yield during leaf drying occurs at lower water potentials (Brodribb and Holbrook 2003). Generally, water stress may damage oxygen-evolving complex and PSII reaction centers (Subrahmanyam et al. 2006). In our study, $F_{v} / F_{m}$ decreased by 9 and $22 \%$ under MWD and SWD, respectively.

The results presented in Table 1 showed that the Chl content of bean plants declined by 14 and 34\%; while Car improved 1.3 and 2.6 folds under MWD and SWD, respectively, relative to well-watered plants. The reduced or unchanged $\mathrm{Chl}$ content depended on the duration and severity of drought stress (Anjum et al. 2011). Drought or heat stresses increase ROS productions which can lead to lipid peroxidation and consequently to $\mathrm{Chl}$ destruction (Foyer et al. 1994). In fact, ROS can cause membrane damage and MDA accumulation and finally cell death. MDA has been considered an indicator for the degree of oxidative stress (Dionisio-Sese and Tobita 1998). In our study, leaf MDA content increased when plants were exposed to water stress. Osmotic adjustment is also an important mechanism to resist drought stress in plants. The osmoregulation substances, such as proline, soluble sugars, and soluble proteins, play vital roles in maintaining osmotic equilibrium and the integrity of membranes under water deficit (Mahajan and Tuteja 2005). Proline accumulation may occur due to an increased activity of pyroline-5-carboxylase reductase and reduced activitys of proline oxidase under stress conditions (Nounjan et al. 2012). As an average, leaf proline content in bean plants increased by water deficit almost 1.8 folds in comparison with well-watered plants. Car as accessory pigments play a critical role in the assembly of the light-harvesting complex and in thermal dissipation of excess light energy (Demmig-Adams and Adams 1992). We observed that the increase in the Car content was closely associated with the water stress level (Table 1). In drought conditions, plants usually increase endogenous Car contents to cope with oxidative stress (Eskling et al. 1997).

According to our results presented in Table 2, WUE increased only under SWD. Zhang et al. (2006) reported that deficit of irrigation could result in higher WUE in spring wheat under an arid environment. Declining of $g_{\mathrm{s}}$ under drought treatment improves WUE when $g_{\mathrm{s}}$ is the dominant factor controlling gas exchange (Li et al. 2011). Water deficiency considerably impaired the yield and yield component-related traits, such as the number of pods per plant, number of grains per pod, 100-grain mass, grain yield per plant and harvest index. Decreasing the yield under water deficit could be a result of a reduction in the Chl content as our data indicated, and consequently, photosynthesis efficiency. Martínez et al. (2007) demonstrated that water stress reduced grain yield up to $70 \%$ in common bean under field conditions. Bean genotypes showed different responses to water deficit in this experiment. The results show that the changes in grain production under water stress and their relationship with the water deficit resistance of bean genotypes varied greatly with the severity of the stress. Among bean genotypes, the lowest decrease of gas-exchange parameters belonged to Pak; in contrast, the highest was recorded in COS12 under water stress conditions, which led to similar trends in yield and yield components. In agreement with this observation, the lowest value of MDA content and the highest increment in proline under water scarcity belonged to Pak.

PAs are ubiquitous aliphatic amines associated with regulation of plant stress tolerance due to their roles in free radical scavenging, osmotic adjustment, and maintaining a cation-anion balance under abiotic stress (Roychoudhury et al. 2011). Exogenously applied PAs could improve drought tolerance of plants by inhibiting lipid peroxidation, increasing WUE and modulating plant metabolism (Sagor et al. 2013). In the current study, spermidine application led to increase in leaf RWC, Chl, Car, and proline contents, $\mathrm{F}_{\mathrm{v}} / \mathrm{F}_{\mathrm{m}}, C_{\mathrm{i}}, g_{\mathrm{s}}, E, P_{\mathrm{N}}$, and $\mathrm{WUE}_{\mathrm{i}}$ in three bean genotypes compared with control. Enhanced RWC, $g_{\mathrm{s}}, E$, and Chl content in spermidine- treated plants resulted in higher $P_{\mathrm{N}}$ and improved $\mathrm{WUE}_{\mathrm{i}}$. It suggests that spermidine is able to influence $P_{\mathrm{N}}$ through increasing $\mathrm{RWC}, g_{\mathrm{s}}$, and $\mathrm{Chl}$, Car, and proline contents under water stress. When RWC falls below $70 \%$, a cascade of physiological processes is initiated with negative impacts for the plant. These changes include turgor loss, decrease in leaf water potential, stomatal closure, decrease in internal $\mathrm{CO}_{2}$ concentration, all of which can lead to impairment of photosynthetic activity (Singh and Reddy 2011). The rises of $P_{\mathrm{N}}$ in concert with the enhanced $g_{\mathrm{s}}$ have contributed to the significant increase in the $\mathrm{WUE}_{\mathrm{i}}$. PAs compounds effectively enhance photosynthesis since they are capable to reverse the stress-induced damage in the photosynthetic apparatus (Sfakianaki et al. 2006). Zhang et al. (2009) reported that exogenous application of PA increased photosynthetic rates in cucumber cultivars. 
Besford et al. (1993) stated that exogenous spermine decreased Chl degradation and protected leaf Rubisco under water stress, while increased contents of spermine were associated with enhanced photosynthesis (Islam et al. 2003). Li et al. (2015) concluded that exogenous spermidine significantly improved leaf RWC and maintained the Chl content better, which demonstrate that spermidine pretreatments delayed leaf senescence in creeping bentgrass under drought stress. Our data clearly showed the direct correlation between spermidine use and Car, proline and $\mathrm{Chl}$ contents in response to water stress. It means that keeping the balance between $\mathrm{Chl}$ and Car biosynthesis and their catabolism were important for plants to deal with water stress. Moreover, accumulated organic solute and enhanced Car metabolism caused by spermidine may be involved in osmotic adjustment and osmoprotection, which explains the higher $\mathrm{Chl}$ and $\mathrm{F}_{\mathrm{v}} / \mathrm{F}_{\mathrm{m}}$ and better photosynthesis regarding the response of water stress. These data suggested that the better stress tolerance of treated plants by spermidine could be associated with increased RWC, Car, proline, and Chl pigment contents, $g_{\mathrm{s}}$ and $E$, which strongly improved $P_{\mathrm{N}}$. Enhanced proline and Car contents in spermidine-treated leaves resulted in lower lipid peroxidation and improved cell membrane stability, as demonstrated by lower MDA concentrations.

In addition, the data in this study also showed that spermidine usage could increase the yield and yield components of bean plants. Increasing grain yield is primarily the result of increased number of pods per plant and number of grains per pod rather than 100-grain mass in spermidine-treated plants. Ndayiragije and Lutts (2007) demonstrated that exogenous putrescine, and to a lesser extent spermidine, improved salt-damaged yield-related characters in rice including grain yield per plant, panicle number, spikelets per panicle, and 1,000-grain mass. Saleethong et al. (2013) stated that the exogenous spermidine application alleviated the adverse effects of

\section{References}

Abedi T., Pakniyat H.: Antioxidant enzyme changes in response to drought stress in ten cultivars of oilseed rape (Brassica napus L.). - Czech J. Genet. Plant 46: 27-34, 2010.

Alburquerque N., Egea J., Burgos L. et al.: The influence of polyamines on apricot ovary development and fruit set. - Ann. Appl. Biol. 149: 27-33, 2006.

Alcázar R., Bitrián M., Bartels D. et al.: Polyamine metabolic canalization in response to drought stress in Arabidopsis and the resurrection plant Craterostigma plantagineum. - Plant Signal Behav. 6: 243-250, 2011.

Anjum S.A., Xie X., Wang L.C. et al.: Morphological, physiological and biochemical responses of plants to drought stress. Afr. J. Agr. Res. 6: 2026-2032, 2011.

Bates L.S., Waldren R.P., Teare L.D.: Rapid determination of free proline for water stress studies. - Plant Soil 39: 205-207, 1973.

Benešová M., Holá D., Fischer L. et al.: The physiology and proteomics of drought tolerance in maize: early stomatal closure as a cause of lower tolerance to short term dehydration.
$\mathrm{NaCl}$ stress on the reproductive processes leading to an improvement in rice yield. Stimulation of reproductive development by PAs has also been reported in apricot (Alburquerque et al. 2006) and cotton (Bibi et al. 2010) but the mechanisms of PAs action on promoting reproductive development are still largely unknown. We think the increase in $g_{\mathrm{s}}, E$, photosynthetic pigment contents, and $P_{\mathrm{N}}$ by spermidine can lead to the yield and yield components improvements in common bean plants. Our results suggested that spermidine is directly involved in mitigation of water stress in bean plants.

Conclusion: Water stress inhibits growth and reduces grain yield of common bean plants through $\mathrm{Chl}$ diminution and photosynthesis inhibition. We conducted experiments with three conventional common bean genotypes. Based on our results, Pak and COS12 appeared to be water stresstolerant and water stress-sensitive, respectively, because of the reduction in some gas-exchange parameters, grain yield, and yield components affected by diminished water availability. The present study also confirmed that spermidine as a free radical scavenger counteracted impressively and alleviated the negative effects of water deficit stress in three bean genotypes, as demonstrated by higher RWC, Chl content, $g_{\mathrm{s}}, C_{\mathrm{i}}, E, P_{\mathrm{N}}$, and increasing grain yield in comparison with control bean. This study also suggests that spermidine induced accumulation of Car and proline, which play a principle role in improving drought tolerance associated with osmotic adjustment and osmoprotection. Likewise, spermidine usage reduced the MDA content, which lowered lipid peroxidation and cell damage, and caused a higher membrane stability. It is proposed that spermidine as a polyamine would help plants resist stress and prevent them from being seriously damaged. Therefore, we can speculate that application of PAs may be useful in common bean for coping with waterstress conditions.

- PLoS ONE 7: e38017, 2012.

Bertolde F.Z., Almeida A.A.F., Pirovani C.P. et al.: Physiological and biochemical responses of Theobroma cacao L. genotypes to flooding. - Photosynthetica 50: 447-457, 2012.

Besford R.T., Richardson C.M., Campos J.L. et al.: Effect of polyamines on stabilization of molecular complexes in thylakoid membranes of osmotically stressed oat leaves. Planta 189: 201-206, 1993.

Bibi A.C., Oosterhuis D.M., Gonias E.D.: Exogenous application of putrescine ameliorates the effects of high temperature in Gossypium hirsutum L. flowers and fruit development. - J. Agron. Crop Sci. 196: 205-211, 2010.

Bota J., Flexas J., Medrano H.: Is photosynthesis limited by decreased Rubisco activity and RuBP content under progressive water stress? - New Phytol. 162: 671-681, 2004.

Brodribb T.J., Holbrook N.M.: Stomatal closure during leaf dehydration, correlation with other leaf physiological traits. Plant Physiol. 132: 2166-2173, 2003.

Centritto M.: Photosynthetic limitations and carbon partitioning 
in cherry in response to water deficit and elevated $\left[\mathrm{CO}_{2}\right]$. - Agr. Ecosyst. Environ. 106: 233-242, 2005.

Chattopadhayay M.K., Tiwari B.S., Chattopadhyay G. et al.: Protective role of exogenous polyamines on salinity-stressed rice (Oryza sativa) plants. - Physiol. Plantarum 116: 192-199, 2002.

Chaves M.M., Maroco J.P., Pereira J.S.: Understanding plant response to drought: from genes to the whole plant. - Funct. Plant Biol. 30: 239-264, 2003.

Demmig-Adams B., Adams W.W. W: Photoprotection and other responses of plants to high light stress. - Annu. Rev. Plant Phys. 43: 599-626, 1992.

Dietz K.J., Pfannschmidt T.: Novel regulators in photosynthetic redox control of plant metabolism and gene expression. - Plant Physiol. 155: 1477-1485, 2011.

Dionisio-Sese M.L., Tobita S.: Antioxidant responses of rice seedlings to salinity stress. - Plant Sci. 135: 1-9, 1998.

Duan H.G., Yuan S., Liu W.J. et al.: Effects of exogenous spermidine on photosystem II of wheat seedlings under water stress. - J. Integr. Plant Biol. 48: 920-927, 2006.

Eskling M., Arvidsson P.O., Åkerlund H.E.: The xanthophylls cycle, its regulation and components. - Physiol. Plantarum 100: 806-816, 1997.

Farooq M., Wahid A., Lee D.J.: Exogenously applied polyamines increase drought tolerance of rice by improving leaf water status, photosynthesis and membrane properties. - Acta Physiol. Plant. 31: 937-945, 2009.

Foyer C.H., Descourvieres P., Kunert K.J.: Photo oxidative stress in plants. - Plant Physiol. 92: 696-717, 1994.

Govindjee.: On the requirement of minimum number of four versus eight quanta of light for the evolution of one molecule of oxygen in photosynthesis: A historical note. - Photosynth. Res. 59: 249-254, 1999.

Groppa M.D., Benavides M.P.: Polyamines and abiotic stress: recent advances. - Amino Acids 34: 35-45, 2008.

Gupta S., Gupta N.: Field efficacy of exogenously applied putrescine in wheat (Triticum aestivum L.) under water-stress conditions. - Indian J. Agr. Sci. 81: 516-519, 2011.

Ioannidis N.E., Cruz J.A., Kotzabasis K. et al.: Evidence that putrescine modulates the higher plant photosynthetic proton circuit. - PLoS ONE 7:e29864, 2012.

Islam M.A., Blake T.J., Kocacinar F. et al.: Ambiol, spermine and aminoethoxyvinylglycine prevent water stress and protect membrane in Pinus strobus under drought. - Tree Struct. Funct. 17: 278-284, 2003.

Kusano T., Berberich T., Tateda C. et al.: Polyamines: essential factors for growth and survival. - Planta 228: 367-381, 2008.

Li W.D., Hou J.L., Wang W.Q. et al.: Effect of water deficit on biomass production and accumulation of secondary metabolites in roots of Glycyrrhiza uralensis. - Russ. J. Plant Physl+ 58: 538-542, 2011.

Li Z., Zhou H., Peng Y. et al.: Exogenously applied spermidine improves drought tolerance in creeping bentgrass associated with changes in antioxidant defense, endogenous polyamines and phytohormones. - Plant Growth Regul. 76: 71-82, 2015.

Lichtenthaler H.K., Wellburn A.R.: Determinations of total carotenoids and chlorophylls a and $\mathrm{b}$ of leaf extracts in different solvents. - Biochem. Soc. T. 11: 591-59, 1983.

Mahajan S., Tuteja N.: Cold, salinity and drought stresses: an overview. - Arch. Biochem. Biophys. 444: 139-158, 2005.

Martínez J.P., Silva H., Ledent J.F. et al.: Effect of drought stress on the osmotic adjustment, cell wall elasticity and cell volume of six cultivars of common beans (Phaseolus vulgaris L.). Eur. J. Agron. 26: 30-38, 2007.

Massacci A., Nabiev S.M., Pietrosanti L. et al.: Response of the photosynthetic apparatus of cotton (Gossypium hirsutum) to the onset of drought stress under field conditions studied by gasexchange analysis and chlorophyll fluorescence imaging. Plant Physiol. Bioch. 46: 189-195, 2008.

Miller G., Suzuki N., Ciftci-Yilmaz S. et al.: Reactive oxygen species homeostasis and signalling during drought and salinity stresses. - Plant Cell Environ. 33: 453-467, 2010.

Misra A.N., Latowski D., Strzalka K.: The xanthophyll cycle activity in kidney bean and cabbage leaves under salinity stress. - Russ. J. Plant Physl+ 53: 102-109, 2006.

Ndayiragije A., Lutts S.: Long term exogenous putrescine application improves grain yield of a salt-sensitive rice cultivar exposed to NaCl. - Plant Soil 291: 225-238, 2007.

Nezhadahmadi A., Prodhan Z.H., Faruq G.: Drought tolerance in wheat. - Sci. World J. 12: 610721, 2013.

Nounjan N., Nghia P.T., Theerakulpisut P.: Exogenous proline and trehalose promote recovery of rice seedling from salt-stress and differentially modulate antioxidants enzymes and expression of related genes. - J. Plant Physiol. 169: 596-604, 2012.

Rosales M.A., Ríos J.J., Cervilla L.M. et al.: Environmental conditions in relation to stress in cherry tomato fruits in two experimental Mediterranean greenhouses. - J. Sci. Food Agric. 89: 735-742, 2009.

Rouhi V., Samson R., Lemeur R. et al.: Photosynthetic gas exchange characteristics in three different almond species during drought stress and subsequent recovery. - Environ. Exp. Bot. 59: 117-129, 2007.

Roychoudhury A., Basu S., Sengupta D.N.: Amelioration of salinity stress by exogenously applied spermidine or spermine in three varieties of indica rice differing in their level of salt tolerance. - J. Plant Physiol. 168: 317-328, 2011.

Sagor G.H.M., Berberich T., Takahashi Y. et al.: The polyamine spermine protects Arabidopsis form heat stress-induced damage by increasing expression of heat shock-related genes. - Transgenic Res. 22: 595-605, 2013.

Saleethong P., Sanitchon J., Kong-ngern K. et al.: Effects of exogenous spermidine (Spd) on yield, yield-related parameters and mineral composition of rice (Oryza sativa L. ssp. indica) grains under salt stress. - Aust. J. Crop. Sci. 7: 1293-1301, 2013.

Sánchez-Rodríguez E., del Mar Rubio-Wilhelmi M., Blasco B. et $a l .:$ Antioxidant response resides in the shoot in reciprocal grafts of drought-tolerant and drought-sensitive cultivars in tomato under water stress. - Plant Sci. 188-189: 86-96, 2012.

Sfakianaki M., Sfichi L., Kotzabasis K.: The involvement of LHCII-associated polyamines in the response of the photosynthetic apparatus to low temperature. - J. Photoch. Photobio. B 84: 181-188, 2006.

Shukla V., Ma Y.M., Merewitz E.: Creeping bentgrass responses to drought stress and polyamine application. - J. Am. Soc. Hortic. Sci. 140: 94-101, 2015.

Singh S.K., Reddy K.R.: Regulation of photosynthesis, fluorescence, stomatal conductance and water-use efficiency of cowpea (Vigna unguiculata [L.] Walp.) under drought. - J. Photoch. Photobio. B 105: 40-50, 2011.

Snider J.L., Collins G.D., Whitaker J. et al.: Electron transport trough photosystem II is not limited by a wide range of water deficit conditions in field-grown Gossypium hirsutum. - J. Agro. Crop Sci. 200: 77-82, 2014. 
Subrahmanyam D., Subash Y.S., Haris A. et al:: Influence of water stress on leaf photosynthetic characteristics in wheat cultivars differing in their susceptibility to drought. Photosynthetica 44: 125-129, 2006.

Sucre B., Suarez N.: Effect of salinity and PEG-induced water stress on water status, gas exchange, solute accumulation, and leaf growth in Ipomoea pescaprae. - Environ. Exp. Bot. 70: 192-203, 2011.

Yin Z.P., Li S., Ren J. et al.: Role of spermidine and spermine in alleviation of drought-induced oxidative stress and photosynthetic inhibition in Chinese dwarf cherry (Cerasus humilis) seedlings. - Plant Growth Regul. 74: 209-218, 2014.
Yue Y., Zhang M., Zhang J. et al.: Overexpression of the AtLOS5 gene increased abscisic acid level and drought tolerance in transgenic cotton. - J. Exp. Bot. 63: 3741-3748, 2012.

Zhang B., Li F.M., Huang G. et al.: Yield performance of spring wheat improved by regulated deficit irrigation in an arid area. - Agr. Water Manage. 79: 28-42, 2006.

Zhang R.H., Li J., Guo S.R. et al.: Effects of exogenous putrescine on gas exchange characteristics and chlorophyll fluorescence of NaCl-stressed cucumber seedlings. Photosynth. Res. 100: 155-162, 2009. 